\title{
Toponímia das cidades pertencentes ao Caminho dos Diamantes: dois séculos de viagens motivadas pela geodiversidade.
}

\author{
Toponymy of the cities belonging to the Caminho dos Diamantes: two centuries of \\ travel motivated by geodiversity.
}

Suzana Fernandes de Paula Doutoranda no P.P.G. Evolução Crustal e Recursos Naturais - DEGEO/UFOP, Brasil

suzanageotur@yahoo.com.br

Paulo de Tarso Amorim Castro Professor orientador-DEGEO/UFOP, Brasil ptacastro@gmail.com

\begin{abstract}
Resumo
As cidades pertencentes ao Caminho dos Diamantes, trecho da Estrada Real no estado Minas Gerais, foram construídas lado-a-lado com as áreas de mineração que deixaram marcas na paisagem. Além do mais, essa região apresenta beleza inigualável devido sua localização e especificidades geológicas e geomorfológicas características do Quadrilátero Ferrífero e Serra do Espinhaço. Em virtude de sua geodiversidade e história intimamente ligada à mineração, o Caminho dos Diamantes apresenta diversas características relacionadas aos aspectos mineiros e geológicos que são expressadas, inclusive, na toponímia dos municípios que a compõe. Esse trabalho pretende fazer um levantamento sobre a origem dos nomes dessas localidades, qualificar e quantificar quais possuem uma influência direta relacionada à geodiversidade e patrimônio geomineiro sendo possível, assim, dimensionar o quão presente é a influência destes aspectos na configuração e identidades destas localidades.
\end{abstract}

Palavras-chave: Caminho dos Diamantes; Toponímia; Patrimônio geomineiro; Geodiversidade.

\begin{abstract}
The cities belonging to the Caminho dos Diamantes, part of the Estrada Real in the state of Minas Gerais, were built side-by-side with the mining areas that left marks on the landscape. What's more, this region has incomparable beauty in function to its location and geological and geomorphological specificities characteristic of the Quadrilátero Ferrífero and Serra do Espinhaço. In function to its geodiversity and history closely linked to mining, the Caminho dos Diamantes presents several characteristics related to the mining and geological aspects that are expressed, including, in the toponymy of the municipalities that compose it. This work intends to make a survey about the origin of the names of these localities, qualify and quantify which have a direct influence related to geodiversity and geological and mining heritage being possible, so, to assess how present is the influence of these aspects on the configuration and identities of these localities.
\end{abstract}

Keywords: Caminho dos Diamantes; Toponymy; Geological and Mining heritage; Geodirvesity 


\section{INTRODUÇÃO}

O trajeto do projeto turístico Estrada Real foi delimitado a partir dos caminhos, outorgados pela realeza, que receberam e que conduziam as Minas Gerais, em meados do século XVIII. Conforme descrito no site do Instituto Estrada Real, estes caminhos foram "percorridos pelos escravos, pelo ouro e pela história”. No total, o eixo principal da Estrada Real, de mais de $1600 \mathrm{~km}$ de extensão, passa por 87 cidades e distritos (76 em Minas Gerais, 3 em São Paulo e 8 no Rio de Janeiro) e possui 80 mil $\mathrm{km}^{2}$ de área de influência. O Caminho dos Diamantes, especificamente, além de possuir notáveis e reconhecidos locais com importante patrimônio histórico, artístico, arqueológico, cultural e arquitetônico, conta também com um imenso potencial geomineiro. Esse trecho da Estrada Real com aproximadamente $400 \mathrm{~km}$ de extensão percorrido ao longo da Serra do Espinhaço, que liga Ouro Preto à Diamantina. Do ciclo do ouro e do diamante restou na existência de cidades, vilas, núcleos populacionais, casario, cultura e costumes conectados pelos caminhos que compõem a Estrada Real. Além do mais, este percurso apresenta diversas oportunidades para o desenvolvimento de um segmento do turismo que possa basear-se no patrimônio mineiro e geológico ainda pouco avaliado em seu potencial. $\mathrm{O}$ interesse por esta região antecede e ultrapassa a criação e objetivos deste referido produto turístico. Nela existem vários locais referenciais de visitação e de permanência de cientistas naturalistas do século XIX que narraram os primeiros passos para a consolidação dos conhecimentos sobre um vasto território, deixando um legado de relatos, roteiros e mapas cujas bases tinham uma visão integrada da natureza, seus recursos, a sociedade e a relação entre estes aspectos.

Ao tratar da possibilidade desta nova ótica patrimonial, há de se referir bem mais do que a estética das feições geológicas e os minerais que foram e são extraídos, esta associação pode ser percebida ainda no contato com as comunidades e nos elementos culturais destas cidades ou vilas localizadas nestas regiões e onde existe a herança ou realidade da mineração. Outro ponto a ser trabalhado são os inúmeros sítios que foram e são utilizados para este fim como minas a céu aberto, galerias, mundéus, sarilhos, coberturas alteradas ou rios, por exemplo, assim como a infraestrutura ao redor que teve que ser criada para o suporte as atividades.

A Toponímia, além de ser a ciência que trata dos nomes das cidades que fazem demonstra aspectos histórico-culturais já que expressa no processo denominativo aspectos importantes da história, cultura e tradição de uma comunidade. Conforme relatado por Seabra (2004), o topônimo é um símbolo linguístico que aponta características, físicas, ambientais e sociais demonstrando situações a respeito da história e da cultura de um povo além de apresentar "função conservadora das tradições e dos costumes de uma comunidade na medida em que se utilizam de sua cultura linguística para nomear acidentes geográficos". 
Em trabalho de campo, utilizando os materiais de navegação disponibilizados pelo Instituto Estrada Real, baseando em pesquisas bibliográficas a respeito do Caminhos dos Diamantes, mineração de ouro, ferro e diamantes, patrimônio geomineiro e toponímia das cidades pertencentes a área do estudo, pretendeu-se averiguar a influência da mineração e da conformação geológica na origem e denominação dessas localidades que hoje configuram um reconhecido produto turístico nacional.

\section{MARCO TEÓRICO SOBRE A MINERAÇÃO NO CAMINHO DOS DIAMANTES}

\subsection{MINERAÇÃO DE OURO}

Existe controvérsias a respeito de onde foi exatamente o local e data de descoberta das minas de ouro. O certo é que primeira grande corrida do ouro no Brasil ocorreu no final do século XVII, a partir da bandeira de Fernão Dias Paes, que saiu de São Paulo até chegar ao Rio das Velhas onde, de acordo com o relato de diversos autores como Barbosa \& Rodrigues (1967) e Eschwege (1833), encontrou - se as primeiras pepitas de ouro que foram associadas ao paládio oxidado, o que, possivelmente foi o motivo para a origem do atual nome da cidade de Ouro Preto. As jazidas de ouro foram encontradas, principalmente, em depósitos aluvionares, com alguns jazimentos em rochas duras, como descreve Sílvio Froes de Abreu, citado por Scliar (1996):

\footnotetext{
o grande desenvolvimento da mineração do fim do século XVII ao fim do século XVIII foi devido ao estado que se achavam o ouro nas jazidas. Não havia necessidade especial de processos para obtê-lo, era só apanhá-lo nos cascalhos e nas baixadas ou nas areias dos ribeirões. Havia ouro livre em pó ou em pepitas, acumulado em grandes quantidades, já criado pela natureza e separado da canga. Com a mais simples aparelhagem fez-se a mineração naquele século. Era uma verdadeira catagem que só necessitava do braço humano sem jeito especial ou inteligência amestrada. Esse acumulo de metal, feito pelas condições naturais durante tempos incontáveis, esgotou em menos de dois séculos de exploração intensiva. Quando foi necessário construir galerias atacar a rocha matriz ou lavar terras de baixo teor declinou a mineração no Brasil (ABREU, 1973).
}

O ciclo do Ouro que durou aproximadamente 100 anos foi um período marcante por fazer com que o Brasil se tornasse responsável por 2/3 da produção aurífera mundial. Outra mudança econômica deu-se através do desenvolvimento de outras regiões da colônia: os campos do Sul se desenvolveram através da pecuária de corte e de transporte. No Sudeste, as vilas que se formaram nos caminhos dos tropeiros desenvolveram o comércio e estimulou-se a agricultura. Mais tarde, com a criação do Caminho Novo, o Rio de Janeiro se transformou no mais importante entreposto da colônia, em virtude do Porto e do comércio que ali desenvolvera. Ao Norte e nordeste, além da 
expansão da pecuária, foi-se estimulado a indústria do sal, couro e aguardente, utilizando o Rio São Francisco como caminho natural.

\subsection{MINERAÇÃO DE FERRO}

A produção e construção de fornalhas para a fabricação de ferro eram proibidas pelos portugueses no Brasil colônia, contudo, com a crise da produção de ouro e através de mudanças políticas em Portugal começaram a incentivar à extração e manufatura do ferro, construindo de diversas fábricas, como as do Morro do Pilar, Ipanema e Congonhas do Campo. Durante o Império a produção e extração ainda eram em pequena escala, utilizando carvão vegetal, com a utilização de mão de obra escrava e financiado pela iniciativa privada, com exceção da fábrica do Ipanema que era comandada pelo governo. Neste mesmo momento foi fundada por Henri Gorceix e idealizada por Dom Pedro II, a Escola de Minas de Ouro Preto, este fato foi muito importante para o desenvolvimento da mineração e metalurgia no Brasil (CASTRO; NALINI; LIMA, 2015).

Segundo o DNPM (2015), durante a Republica, em 1907, criou-se o Serviço Geológico e Mineralógico Brasileiro (atual CPRM - Serviço Geológico do Brasil), vinculado ao Ministério da Indústria, Viação e Obras Públicas e em 1910, segundo Castro, Nalini e Lima (2015), no XI Congresso Geológico Internacional, que aconteceu na Suécia, difundiu informações sobre a qualidade do minério de ferro nacional apresentando um trabalho intitulado "Balanço das Riquezas em Minério de Ferro". Este fato fez com que diversos produtores de aço do mundo inteiro interessassem e adquirissem terras nas regiões de Itabira, Nova Lima e Itabirito. Naquela época, a Constituição brasileira dizia que o proprietário do solo era também proprietário do subsolo e dos bens minerais nele existentes.

Segundo IBRAM (2013), o Brasil é o segundo maior produtor de minério de ferro e Minas Gerais é o estado minerador mais importante do Brasil, extraindo mais de 160 milhões de toneladas de minério de ferro por ano. O estado é responsável por67\% da produção, enquanto o Para produz $29,3 \%$ e os demais 3,7\%. As maiores empresas produtoras no Brasil são Vale $(84,52 \%)$, Samarco $(6,29 \%), \operatorname{CSN}(5,45 \%), \operatorname{MMX}(2,03 \%)$ e Usiminas $(1,71 \%)$.

\subsection{MINERAÇÃO DE DIAMANTES}

A única certeza que se tem a respeito da descoberta e início da extração de diamantes no Brasil é que estas se deram em decorrência da mineração de ouro a partir da prática de mineração em aluviões no início do século XVIII e, posteriormente, em larga escala na Serra do Espinhaço. Existem alguns relatos de que já 1729 descobriram-se diamantes na região do Tejuco (Diamantina), 
na comarca do Serro Frio e outras jazidas localizadas na região dos rios Jequitinhonha, Araçuaí, Pardo, Paraúna e tributários menores. As principais lavras localizavam-se no próprio Tejuco e nos distritos de Milho Verde, São Gonçalo, Rio Manso, Caeté-Mirim, Inhaí, Gouveia, Paraúna, Mendanha, Chapada, Rio Pardo e Rio Preto.

Em 1772 foi fundada a Real Extração, que consistia na extração realizada pela fazenda real e era regulamentada pelo Regimento Diamantino. Este regime era aplicado apenas em Minas Gerais, no Distrito ou Demarcação de Diamantina, em virtude de ser o único local que era permitido à exploração legal de diamantes. Já, por volta dos anos de 1840, os contrabandos e a obtenção de concessões de lavras foram se tornando mais fáceis e a região invadida por inúmeros mineradores dificultando e dispersando os últimos remanescentes da empresa real (BENITEZ, 2009).

A fim de coibir a violência de movimentos rebeldes financiados pelo comércio de diamantes foi estabelecido uma certificação para o comércio internacional de diamantes brutos denominado Processo de Kimberly. Assim, foi referendada pelo Congresso Nacional pela lei número 10.743 de 09/03/200 uma medida provisória que institui os termos de exigência do referido processo ao comércio, importação e exportação no Brasil.Segundo o DNPM (2010), o Brasil contribui com $7,5 \%$ da reserva mundial, que em 2009, correspondia em 627 milhões de quilates sendo que Mato Grosso detém $73 \%$ da reserva nacional, enquanto Minas Gerais cerca de $25 \%$.

\section{PRODUTO TURÍSTICO ESTRADA REAL: O CAMINHO DOS DIAMANTES}

Assim, além de ter sido o principal caminho de escoamento da riqueza mineral do país, a Estrada Real passou a exercer papel fundamental no desenvolvimento cultural, político e socioeconômico do Brasil.

Segundo o site do Instituto Estrada Real, o Caminho Velho foi a primeira via a ser aberta pela Coroa Portuguesa e possui 710 km de extensão, ligando as cidades de Paraty a Ouro Preto. Já, com 400 km de extensão pela Reserva da Biosfera do Espinhaço, o Caminho dos Diamantes (Ouro Preto a Diamantina), existiu em função da descoberta e exploração de diamantes. O caminho de Sabaraçu (antigo nome dado a Serra da Piedade), com 160km de extensão, teve seu início devido a crença de que o minério de ferro que brilhava ao contato com a luz solar, fosse ouro. Assim criaram uma rota alternativa entre Ouro Preto (Caminho Velho) e Barão de Cocais (Caminho dos Diamantes). Por fim, o Caminho Novo passou a ser uma alternativa mais rápida e fácil ao Caminho Velho, com 515 km, unindo as cidades de Ouro Preto e Rio de Janeiro que se tornara em 1763 a capital da colônia portuguesa na América do Sul, justamente em função da proximidade com a região aurífera. 
Os marcos da Estrada Real estão espalhados por todas as vias principais ao longo dos 4 Caminhos. Geralmente, encontram-se em pontos estratégicos como pontos de visitação, bifurcações ou locais que possam gerar dúvida ao viajante que caminho deva seguir. Conforme ilustrado na foto a seguir, estes marcos foram feitos de concreto, são padronizados, demonstram as coordenadas geográficas e as cidades (com distância em quilômetros) mais próxima ao local.

Para agregar informações, autonomia e maiores possibilidades de navegação o Instituto Estrada Real disponibiliza em seu site algumas ferramentas que podem ser baixados pelos viajantes. Foram elaboradas planilhas descritivas de cada trecho. Nelas é possível visualizar a distância a ser percorrida, a direção a ser tomada e a descrição de pontos de referência para que não sejam usados apenas os marcos como orientação. Outro auxilio no que se refere a dificuldade do trecho trata-se de um gráfico altimétrico e de informações básicas e de fácil entendimento expostos no site. Além da percepção visual o viajante obtém informações sobre os critérios utilizados para definir o grau de dificuldade de cada trecho.

O recorte para desenvolvimento do presente trabalho é o Caminho dos Diamantes que, de acordo com o site do Instituto Estrada Real, seu eixo principal possui aproximadamente $400 \mathrm{~km}$ de extensão, abrangendo 50 municípios ligando os municípios de Ouro Preto e Diamantina (IER, 2015). Este caminho passou a ter importância após 1729, quando as pedras preciosas descobertas no Arraial do Tejuco (Diamantina) passaram a exercer grande impacto econômico no Brasil e em Portugal mudando a realidade da capitania de Minas Gerais, que até então crescia em virtude da mineração de ouro. A partir de então, a Estrada Real tem seu prolongamento de Ouro Preto até Diamantina conforme exposto no mapa.

Em virtude de sua geodiversidade e história, grande parte do patrimônio histórico e arquitetônico do estado de Minas Gerais foi construído lado-a-lado com as áreas de mineração e deixaram marcas na paisagem e na estrutura histórico-social dessas localidades. Uma característica importante e, por muitas vezes, desconsiderada é a toponímia das cidades, distritos e povoados do Caminho dos Diamantes, este fato esta diretamente influenciado pela (busca e uso da) geodiversidade. Além das indígenas, essas localidades sofreram influencias de viajantes, dos escravos que trabalhavam nas fazendas e mineração, dos garimpeiros, tropeiros, enfim, de todos àqueles que foram responsáveis pela consolidação daqueles locais. Bem mais do que a relação com as atividades de mineração e com as características das geoformas destes locais, estes nomes também remetem às culturas e tradições, representando características importantes destas comunidades. 


\section{Mapa dos Municípios do Caminho dos Diamantes da Estrada Real}

Legenda

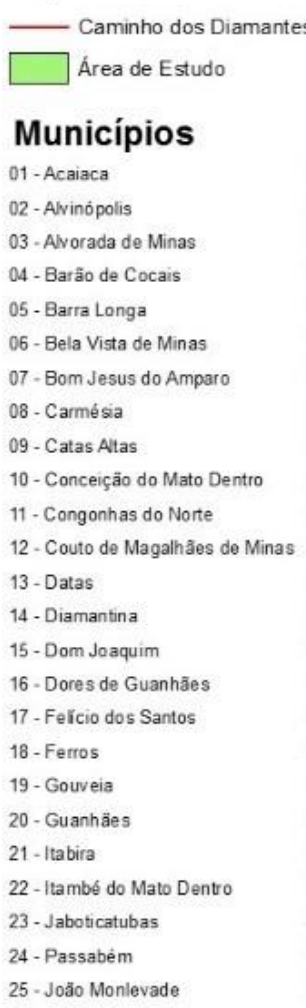

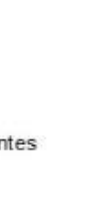

Sistema de Coordenadas Geográficas Sirgas2000 UTM 23S Fontes: IBGE 2014

Autoria: Suzana Fernandes de Paula. 2017
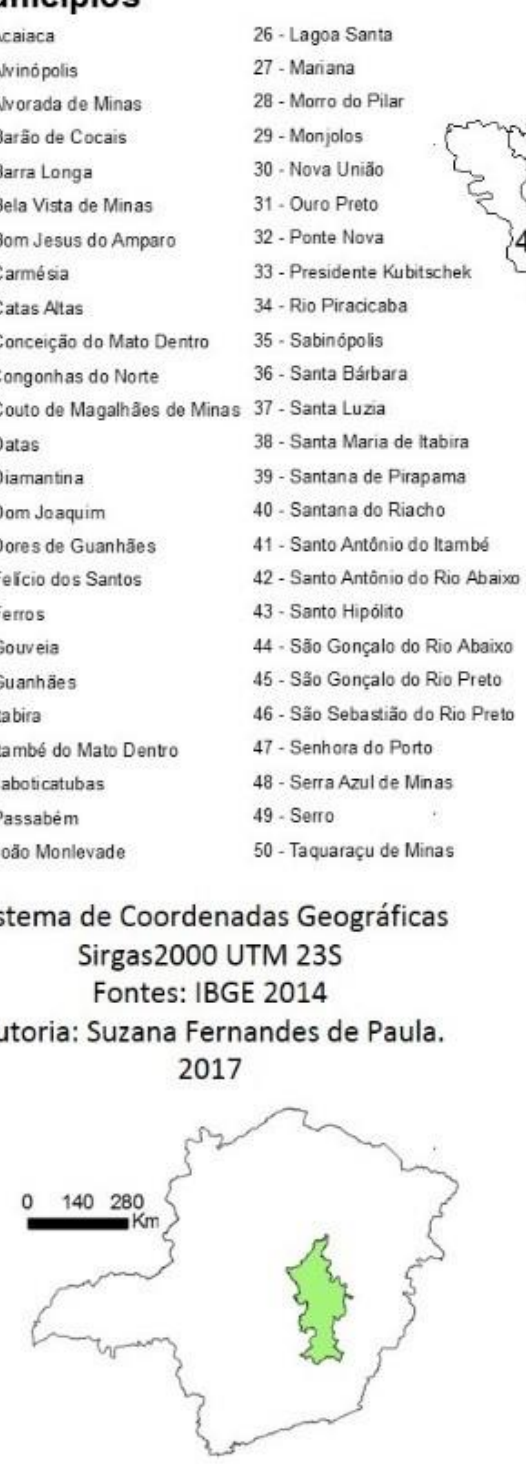

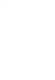


das cidades, distritos e povoados desta região. No Caminho dos Diamantes, este fato é diretamente influenciado pela (busca e uso da) geodiversidade. Além das indígenas, essas localidades sofreram influencias dos próprios viajantes, dos escravos que trabalhavam nas fazendas e mineração, dos garimpeiros, tropeiros, enfim, de todos àqueles que foram responsáveis pela consolidação daqueles locais. Bem mais do que a relação com as atividades de mineração e com as características das geoformas destes, estes nomes também remetem às culturas e tradições, representando características importantes destas comunidades. Ao fazer uma análise com enfoque linguístico e sincrônico que, segundo Carvalho (2012), consiste na "analise toponímica com a finalidade de estudar os processos de constituição mórfica e apontar as diferentes procedências" foi possível descrever quão importante é a geodiversidade no inconsciente coletivo destas populações pioneiras.

Para representação desta interpretação semântica, a taxonomia (interpretação dos nomes dos lugares partindo de sua relação com a natureza física ou antropocultural) foi distribuída, por Carvalho (2012) da seguinte forma:

Ordem Física

Astrotopônimos

Cardinotopônimos

Cromotopônimos

Dimensiotopônimos Fitotopônimos

Geomorfotopônimos

Hidrotopônimos

Litotopônimos

Metereotopônimos

Morfotopônimos

Zootopônimos
Ordem Antropocultural

Animotopônimos ou

Animotopônimos ou Nootopônimos

Antropotopônimos

Axiotopônimos

Corotopônimos

Cronotopônimos

Dirrematotopônimos

Ecotopônimos

Ergotopônimos

Etnotopônimos

Hierotopônimos

Hagiotopônimos

Histotiotopônimos

Numerotopônimos

Poliotopônimos

Sociotopônimos

Somatopônimos

\section{Relação}

Corpos celestes

Posições geográficas

Cores

Características do próprio acidente

Vegetais

Formas topográficas

Hidrografia

Minerais

Fenômenos atmosféricos

Formas geográficas

Animais

Vida psíquica e espiritual

Nomes próprios e individuais

Títulos que acompanham o nome

Recuperação de nomes de países, cidades ou regiões Tempo

Frases ou enunciados linguísticos

Habitação

Elementos da cultura material

Elementos étnicos

Elementos sagrados

Nomes de santos do Hagiológio romano.

Movimentos de cunho histórico-social Numerais

Aglomerados populacionais

Atividades profissionais ou pontos de encontro

Relação metafórica com partes do corpo humano ou animal

Tabela 1- Interpretação Semântica. Fonte: Adaptado de Carvalho (2012). 


\section{METODOLOGIA}

- Compilação bibliográfica e cartográfica.

- Visitas de campo para a Inventariação dos Lugares de Interesse Geológico e Mineiros

- Confecção de mapas temáticos

- Confecção do Guia Geoturístico do Caminho dos Diamantes (Estrada Real, MG).

\section{RESULTADOS OBTIDOS}

Ao apresentarmos os nomes, a origem, a motivação e a história que apresentam a etimologia das palavras que dão nome às localidades (cidades e distritos) pertencentes ao Caminho dos Diamantes (ER - MG), temos o seguinte cenário:

\begin{tabular}{|c|c|c|c|c|}
\hline Topônimo & Taxonomia & Município & Origem & Motivação \\
\hline $\begin{array}{l}\text { Alvorada de } \\
\text { Minas }\end{array}$ & Metereotopônimo & $\begin{array}{l}\text { Alvorada de } \\
\text { Minas }\end{array}$ & Portuguesa & $\begin{array}{l}\text { Sugestão de pessoas que lutavam } \\
\text { pela emancipação do local e } \\
\text { alegavam que esta conquista seria } \\
\text { um "alvorecer". }\end{array}$ \\
\hline $\begin{array}{l}\text { Barão de } \\
\text { Cocais }\end{array}$ & Axiotopônimo & $\begin{array}{l}\text { Barão de } \\
\text { Cocais }\end{array}$ & Portuguesa & $\begin{array}{l}\text { Homenagem ao patrono do } \\
\text { município, Tenente Coronel José } \\
\text { Feliciano Pinto Coelho da Cunha, } \\
\text { o Barão de Cocais }\end{array}$ \\
\hline $\begin{array}{l}\text { Bento } \\
\text { Rodrigues }\end{array}$ & Antropotopônimo & Mariana & Portuguesa & $\begin{array}{l}\text { Bento Rodrigues foi "Sertanista } \\
\text { de São Paulo que tomou parte da } \\
\text { destruição de Vila Rica em } 1631 \text { ", } \\
\text { CARVALHO (2012) apud } \\
\text { FRANCO (1968) }\end{array}$ \\
\hline $\begin{array}{l}\text { Bom Jesus do } \\
\text { Amparo }\end{array}$ & Hagiotopônimo & $\begin{array}{l}\text { Bom Jesus do } \\
\text { Amparo }\end{array}$ & Portuguesa & $\begin{array}{l}\text { Em decorrência da imagem de } \\
\text { Bom Jesus adquirida na cidade de } \\
\text { Amparo em Portugal. }\end{array}$ \\
\hline Camargos & Antropotopônimo & Mariana & Portuguesa & $\begin{array}{l}\text { Em homenagem a Tomás Lopes } \\
\text { de carvalho e sua família que } \\
\text { estabeleceram-se no local em } \\
\text { virtude da mineração }\end{array}$ \\
\hline Catas Altas & $\begin{array}{l}\text { Sociotopônimo/ } \\
\text { Geomorfotopônimo }\end{array}$ & Catas Altas & Portuguesa & $\begin{array}{l}\text { Em virtude das escavações em } \\
\text { decorrência da mineração. }\end{array}$ \\
\hline Cocais & Fitotopônimo & $\begin{array}{l}\text { Barão de } \\
\text { Cocais }\end{array}$ & Portuguesa & $\begin{array}{l}\text { Em virtude de ao redor da igreja } \\
\text { da localidade, antigamente, ser } \\
\text { rodeada de coqueirais. }\end{array}$ \\
\hline $\begin{array}{l}\text { Conceição do } \\
\text { Mato Dentro }\end{array}$ & Hagiotopônimo & $\begin{array}{l}\text { Conceição do } \\
\text { Mato Dentro }\end{array}$ & Portuguesa & $\begin{array}{l}\text { Em homenagem a Nossa Senhora } \\
\text { da Conceição e segundo } \\
\text { CARVALHO (2012) apud } \\
\text { BEAUREPAIRE (2007), o } \\
\text { substantivo mato, muitas vezes } \\
\text { designava roça. }\end{array}$ \\
\hline Córregos & Hidrotopônimo & $\begin{array}{l}\text { Conceição do } \\
\text { Mato Dentro }\end{array}$ & Portuguesa & $\begin{array}{l}\text { Locais que ainda hoje são } \\
\text { chamados de cânions artificiais } \\
\text { em decorrência das técnicas e } \\
\text { geoformas oriundas da } \\
\text { mineração. }\end{array}$ \\
\hline Diamantina & Litotopônimo & Diamantina & Portuguesa & $\begin{array}{l}\text { Deve-se a mineração dos } \\
\text { diamantes. }\end{array}$ \\
\hline
\end{tabular}




$\begin{array}{llll}\text { Ipoema } & \text { Zootopônimo } & \text { Itabira } & \text { Indígena (tupi) } \\ \text { Itambé do } & \text { Litotopônimo } & \text { Itabira } & \begin{array}{l}\text { Indígena } \\ \text { (tupi) }\end{array} \\ \text { Mato Dentro } & & & \text { (t) }\end{array}$

Significa "Ave que canta" Ita = a pedra; també $=$ mole, acrescido do complemento Mato Dentro.

$\begin{array}{llll}\text { Mariana } & \text { Antropotopônimo } & \text { Mariana } & \text { Portuguesa } \\ \text { Milho Verde } & \begin{array}{l}\text { Antropotopônimo/ } \\ \text { Fitotopônimo }\end{array} & \text { Serro } & \text { Portuguesa } \\ & & & \end{array}$

\begin{tabular}{|c|c|c|c|c|}
\hline & & & & \\
\hline $\begin{array}{l}\text { Morro da } \\
\text { Água Quente }\end{array}$ & Geomorfotopônimo & Catas Altas & Portuguesa & $\begin{array}{l}\text { Referencia às possíveis fontes } \\
\text { termais que existiu na região. }\end{array}$ \\
\hline $\begin{array}{l}\text { Morro do } \\
\text { Pilar }\end{array}$ & Geomorfotopônimo & Morro do Pilar & Portuguesa & $\begin{array}{l}\text { Refere-se a padroeira do então } \\
\text { Morro de Gaspar Soares (nome } \\
\text { de um fazendeiro local). }\end{array}$ \\
\hline Ouro Preto & Litotopônimo & Ouro Preto & Portuguesa & $\begin{array}{l}\text { Em virtude da descoberta de um } \\
\text { ouro escura (coberto de óxido de } \\
\text { ferro) naquela localidade. }\end{array}$ \\
\hline Santa Barbara & Hagiotopônimo & Santa Barbara & Portuguesa & $\begin{array}{l}\text { Homenagem à padroeira do local } \\
\text { e também conhecida como } \\
\text { padroeira dos mineradores. }\end{array}$ \\
\hline $\begin{array}{l}\text { Santa Rita } \\
\text { Durão }\end{array}$ & Antropotopônimo & Mariana & Portuguesa & $\begin{array}{l}\text { Homenagem ao poeta Frei José } \\
\text { da Santa Rita Durão. }\end{array}$ \\
\hline $\begin{array}{l}\text { Santo Antônio } \\
\text { do Norte }\end{array}$ & $\begin{array}{l}\text { Hidrotopônimo e } \\
\text { Hagiotopônimo }\end{array}$ & $\begin{array}{l}\text { Conceição do } \\
\text { Mato Dentro }\end{array}$ & Portuguesa & $\begin{array}{l}\text { Descoberta de ouro às margens } \\
\text { do rio Santo Antônio. }\end{array}$ \\
\hline $\begin{array}{l}\text { São Gonçalo } \\
\text { do Rio das } \\
\text { Pedras }\end{array}$ & Hagiotopônimo & Serro & Portuguesa & Homenagem ao Santo Padroeira \\
\hline Serro & Geomorfotopônimo & Serro & Portuguesa & $\begin{array}{l}\text { Grafado com "C" Cêrro é muito } \\
\text { comum na língua espanhola e } \\
\text { significa pequeno monte } \\
\text { penhascoso e com "S", sob a } \\
\text { influência da serra. }\end{array}$ \\
\hline Três Barras & $\begin{array}{l}\text { Numerotopônimo e } \\
\text { Hidrotopônimo }\end{array}$ & Serro & Portuguesa & $\begin{array}{l}\text { Em virtude do encontro de três } \\
\text { rios. }\end{array}$ \\
\hline Vau & Hidrotopônimo & Diamantina & Portuguesa & $\begin{array}{l}\text { Trecho de rio raso que possibilita } \\
\text { a passagem a pé, a cavalo ou de } \\
\text { veículos. }\end{array}$ \\
\hline
\end{tabular}

Tabela 2 - Toponímia dos nomes dos LIGEMs do Caminhos dos Diamantes. Fonte: Adaptado de Carvalho, 2012.

Ao observarmos os topônimos dos Lugares de Interesse Geológico e Mineiro (LIGEMs) selecionados para o desenvolvimento deste trabalho nota-se que, embora alguns locais tenham uma dupla classificação, os aspectos físicos relacionados sobressaem aos aspectos antropoculturais.

Como principais fatores físicos podemos relacionar a origem dos nomes destes LIGEMs às questões geomorfológica, hidrogeológicas, geológicas, mineração e, em menor escala, características relacionadas à fitologia e zoologia. 


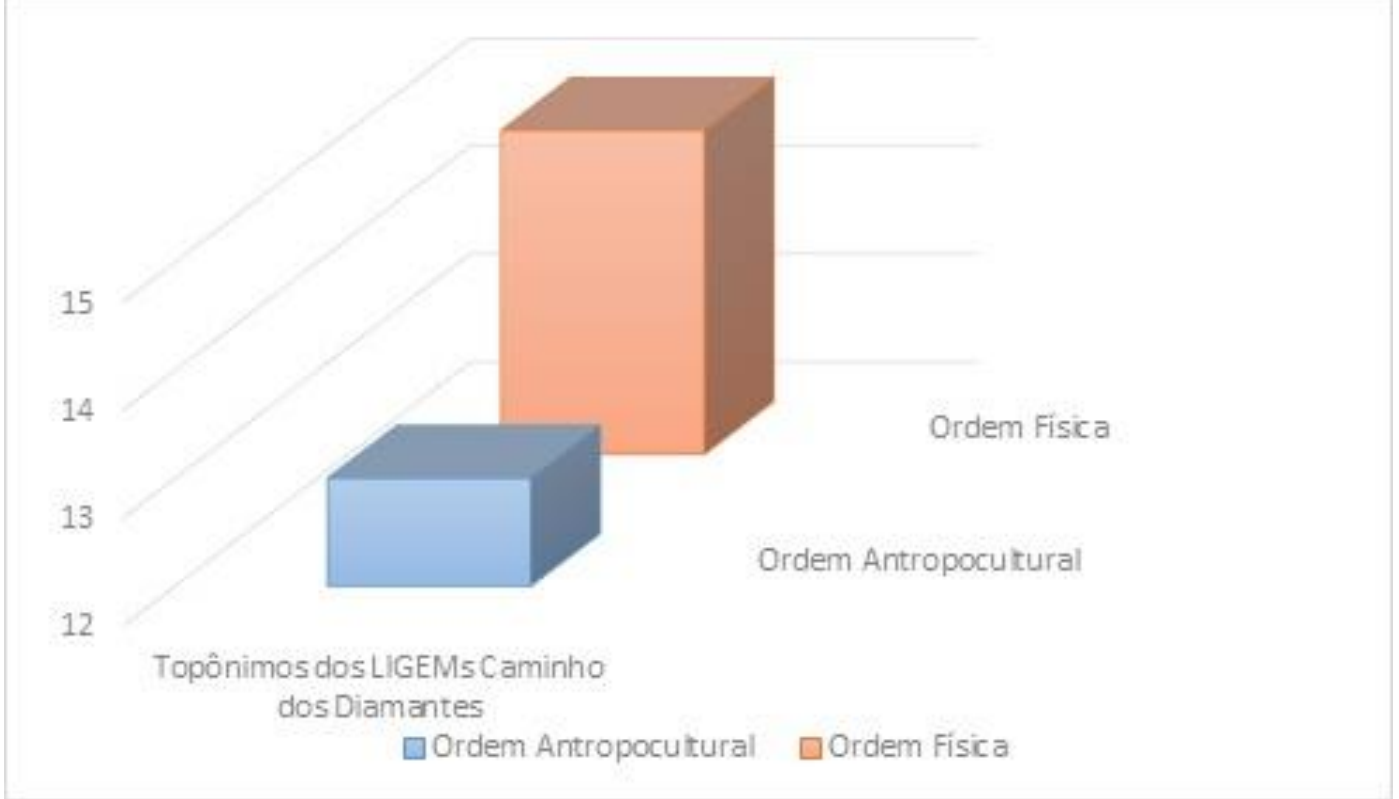

Gráfico 1- Ordem toponímica dos municípios do Caminho dos Diamantes. Fonte: PAULA, 2016.

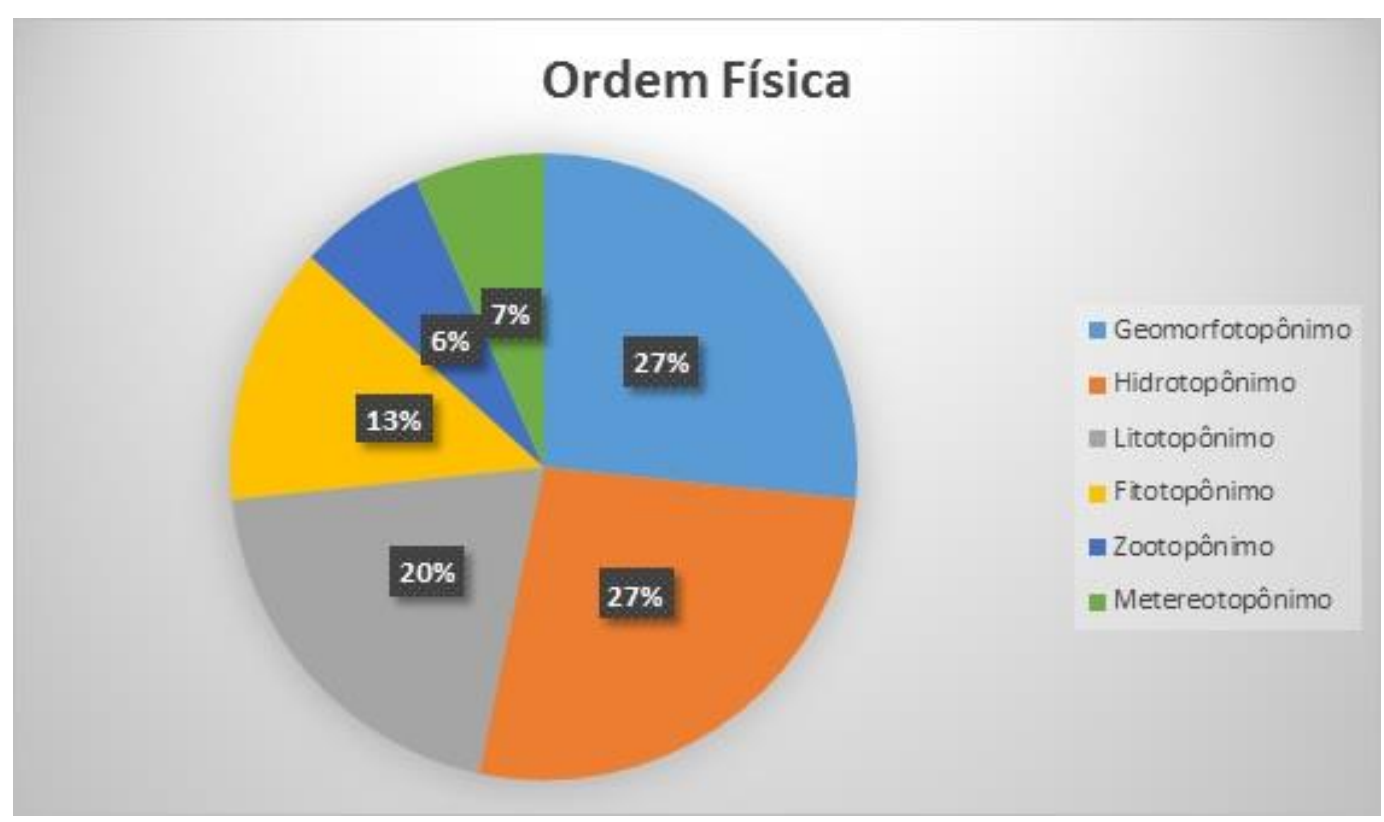

Gráfico 2 - Distribuição da toponímia de ordem física dos municípios do Caminho dos Diamantes. Fonte: PAULA, 2016.

Contudo, quando tratamos do aspecto antropocultural, percebemos o quão presente é a cultura e tradição destas comunidades quando relacionam os topônimos às questões de mineração e tropeirismo, apesar de a maioria dos casos apontarem a religiosidade como mais presente neste quesito.

Sendo assim, podemos afirmar que a toponímia, representa mais que o ato de nomear localidades, é herança reconhecimento de culturas passadas e balizador identitário de um povo já que, conforme Jackson (1920) considera, "o ato de nomear, o espaço é simbolicamente transformado em lugar, que, por sua vez, é um espaço com história”. 


\section{Ordem Antropocultural}

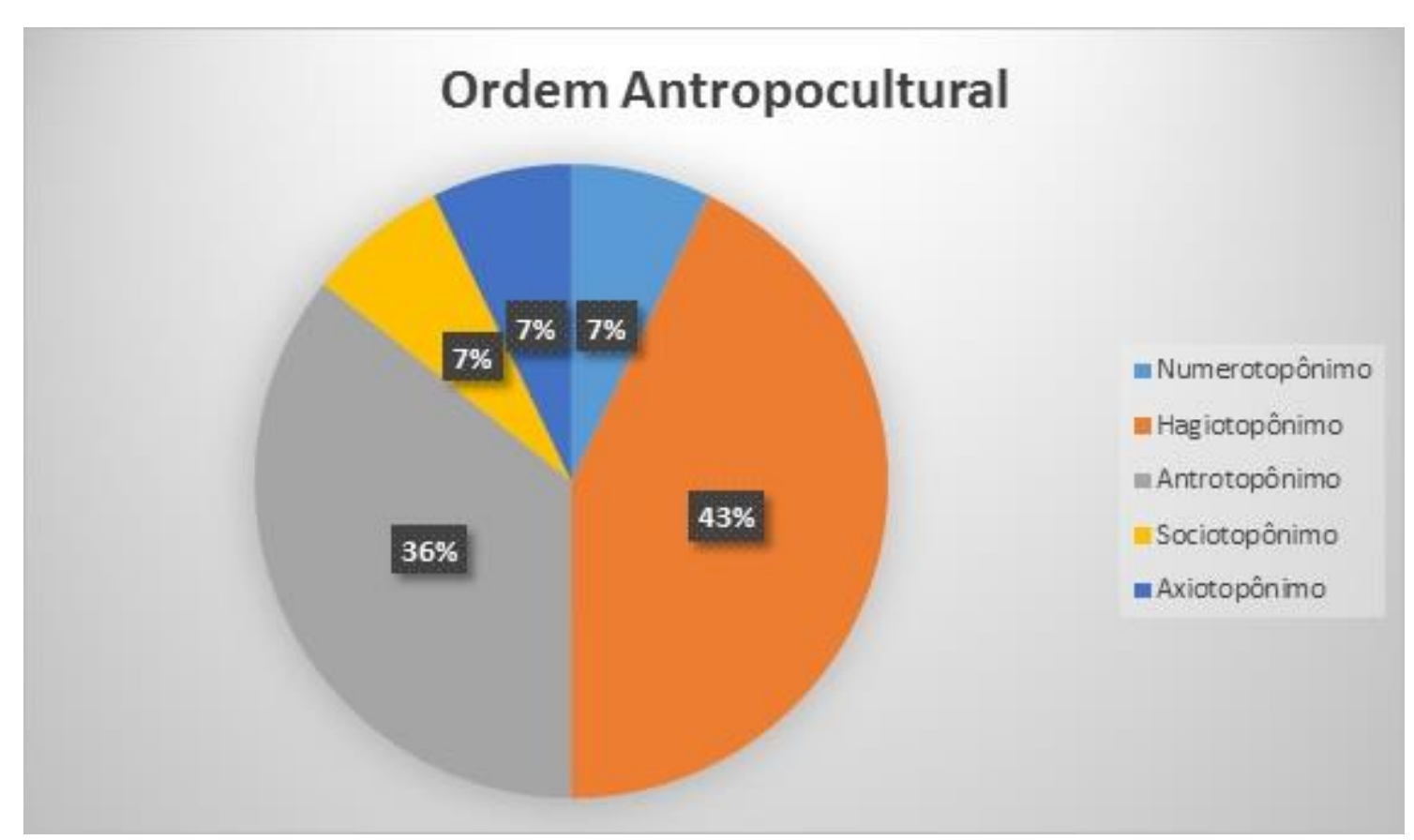

Gráfico 3 - Distribuição da toponímia de ordem antropocultural dos LIGEMs do Caminho dos Diamantes. Fonte: PAULA, 2016.

\section{CONCLUSÕES}

Investigar a toponímia dos lugares pertencentes ao Caminho dos Diamantes requer estudos interdisciplinares já que por detrás dos nomes destes locais encontram-se mais que aspectos geológicos e mineiros, é possível identificar características ligadas às pessoas, histórias, culturas e patrimônio, determinando territórios e identidades. Esse trabalho procurou proporcionar um olhar aos aspectos da toponimia regional ligados aos patrimônios geológico e mineiro ao longo da Estrada Real em sua conexão entre o distrito diamantino, o distrito do Ouro e Quadrilátero Ferrífero, aproximando-os aos valores humanos, culturais e históricos. Desta forma, podemos afirmar que a toponímia é uma expressão da identidade local e, em locais como no Caminho dos Diamantes onde a ocupação deu-se através da exploração de ouro, ferro e diamantes, fica explicitado quanto a geodiversidade local influencia na percepção, descrição e identidade regional.

\section{REFERENCIAS}

ANDRADE, R. K. Vissungo com Angu: Histórias e memórias da produção e consumo de fubá no Alto Jequitinhonha. 2013. 157f. Dissertação (Mestrado em História) - Pontifícia Universidade Católica de São Paulo.

ARNDT, J. R. L. Entre a tradição e a modernidade: sustentabilidade do desenvolvimento pelo turismo em uma comunidade tradicional de Minas Gerais. 2007. 332f. Dissertação de Mestrado. FEAD - Centro de Gestão Empreendedora. 
]BECKER, L. C. PEREIRA, D. O Projeto Minas-Rio e o desafio do desenvolvimento territorial integrado e sustentado: a grande mina em Conceição do Mato Dentro. In: FERNANDES, F. R. C, ENRIQUEZ, M. A. R. S.; ALAMINO, R. C. J. (eds). Recursos minerais e sustentabilidade territorial. Brasília: MCT-CETEM, 2011

BENITEZ, L. Províncias diamantíferas de Minas Gerais: uma proposta para a caracterização de populações de diamantes típicas como subsidio a certificação de Kimberley. 2009. Tese (Doutorado) - Universidade Federal de Minas Gerais, Instituto de Geociências.

CALAES, G. D.; FEREIRA, G. E. (Eds). A Estrada Real e a transferência da corte portuguesa: Programa Rumys - Projeto Estrada Real. Rio de Janeiro: CETEM / MCT / CNPq /CYTED, 2009.

CANSTATT, O. 2002. Brasil: terra e gente, 1871. Brasília: Senado Federal. 448 p.

CARVAlHO, P. S. L; SILVA, M. M; ROCIO, M. A. R. Minério de Ferro. Biblioteca Digital BNDS. 39p. 2013. Disponível em: <https://web.bndes.gov.br/bib/jspui/bitstream/1408/4802/1/ BS\%2039\%20min\%C3\%A9rio\%20de\%20ferro_P.pdf >

CASTRO, P.T.A.; NALINI JUNIOR, H.A.; LIMA, H. M. Entendendo a Mineração no Quadrilátero Ferrífero. Belo Horizonte: Ecológico, 2011b. v. 1.93p

CETEM - Centro de Tecnologia Mineral. Disponível em: <http://www.cetem. gov.br/>Acesso em 2015.

CHAVES, M.L.S.C; CHAMBEL, L. Diamantes do médio rio Jequitinhonha, Minas Gerais: qualificação gemológica e análise granulométrica. Rem: Rev. Esc. Minas, v.57, n.4, Ouro Preto Oct./Dec. 2004.

CLAVAL, Paul. A Geografia Cultural. 2.ed. Florianópolis: EdUFSC, 2001.

CODEMIG - Companhia de Desenvolvimento Econômico de Minas Gerais. Disponível em: <http://www.codemig.com.br/> Acesso em 2015 e 2016.

CEXBARRA - Comissão Externa do Rompimento de Barragem na Região de Mariana - MG. Relatório Preliminar. 2015. Disponível em: <http://www2. camara.leg.br/atividadelegislativa/comissoes/comissoes-temporarias/externas/55a-legislatura /rompimento-de-barragemna-regiao-de-mariana-mg/documentos/outros-documentos/relatorio-apresentado-em-15-12-2015>.

Acesso em 2016.

CPRM - Companhia de Pesquisa de Recursos Minerais. Ministério das Minas e Energia. Secretaria De Geologia, Mineração e Transformação Mineral. Serviço Geológico do Brasil. Brasília/DFBrasil. Disponível em: 〈http://www.cprm.gov.br/publique/media/ quadrilatero.pdf> Acesso em 2015 e 2016.

DNPM - Departamento Nacional de Produção Mineral. Disponível em: <http://www2. dnpm.gov.br/conteudo.asp?IDSecao=45\&IDPagina=35> 
GONÇALVES, R. N. Diagnóstico ambiental da bacia do rio Jequitinhonha: diretrizes gerais para a ordenação territorial. Salvador: Fundação IBGE, 1997. 64p.

IBGE. Biblioteca IBGE. Disponível em: 〈http://biblioteca.ibge.gov.br/> Acesso em 2005 e 2006.

IBRAM. Instituto Brasileiro de Mineração. Disponível em: <http://www.ibram.org.br/sites/ 1300/1382/00004035.pdf>.

IER - Instituto Estrada Real. Disponível em: <http://www.institutoestradareal.com.br/>

JACKSON, P. Maps of meaning. An introduction to cultural geography. Londres: Routledge, 1992.

MARCOLIN. N. Os primeiros anos da siderurgia. Pesquisa Fasep, 2010. Disponível em: $<$ http://revistapesquisa.fapesp.br/wp-content/uploads/2012/07/008-009-173.pdf?2125d7> Acesso em 2015.

MINISTÉRIO DO TURISMO. Introdução à regionalização do Turismo. Brasília, 2007.

MORAES, F.B. De arraiais, vilas e caminhos: a rede urbana das Minas coloniais. In: RESENDE, M.E.L.; VILLALTA, TA, L.C. História de Minas Gerais. As Minas Setecentistas. Belo Horizonte: Autêntica, 2007. Vol. 1.

PAULA, S. F; CASTRO, P. T. A. Protocolo Protocolo de avaliação e inventariação de lugares de interesse geológico e mineiro. Publicado em Set/ 2014. Campinas, SeTur/SBE. Pesquisas em Turismo e Paisagens Cársticas, v.7, n.1/2, 2014.

PIETRO, C. A mineração e o novo mundo. São Paulo: Cultrix, 1968.

RENGER, F. E. A origem histórica das estradas reais nas Minas Setecentistas. In: RESENDE, M. E. F. L.; VILlALTA, L. C. (orgs.) As Minas Setecentistas, volume 1. Belo Horizonte: Autêntica, 2007.

ROCHA JUNIOR, D.; VIEIRA JUNIOR, W.; CARDOSO, R.C. Viagem pela Estrada Real dos Goyazes. Brasília: Paralelo 15, 2006.

SANTOS, M. Estradas reais: introdução ao estudo dos caminhos do ouro e do diamante no Brasil. Belo Horizonte: Estrada Real, 2001. 179p.

SEABRA, M. C. T. C. de. A formação e a fixação da língua portuguesa em Minas Gerais: a toponímia da Região do Carmo, 2004, 368 f. Tese (Doutorado em Linguística), Programa de PósGraduação em Estudos Linguísticos, Universidade Federal de Minas Gerais, Belo Horizonte.

SEEMANN, J. A. Toponímia como construção histórico-cultural: o exemplo dos municípios do estado do Ceará. Revista Vivencia, n. 29, 2005. p. 207-224 